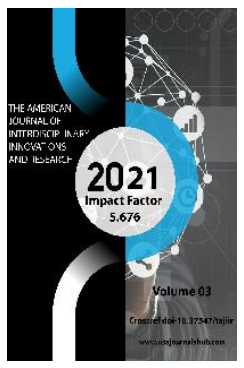

Copyright: Original content from this work may be used under the terms of the creative commons attributes 4.0 licence.

\section{A Review On: Analysis Of The Properties Of Thermal Insulation Materials}

\author{
Azim Rasulovich Abdullaev \\ Assistant, Department Of “Metrology, Standardization And Quality Management", \\ Namangan Institute Of Engineering And Technology, Namangan, Republic Of Uzbekistan \\ Xayotbek Mansurjon O'g'li Rafiqov \\ Student, Department Of “Metrology, Standardization And Quality Management", Namangan \\ Institute Of Engineering And Technology, Namangan, Republic Of Uzbekistan \\ Isroiljonova Nizomjon Qizi Zulxumor \\ Student, Department Of “Metrology, Standardization And Quality Management”, Namangan \\ Institute Of Engineering And Technology, Namangan, Republic Of Uzbekistan
}

\title{
ABSTRACT
}

Clothing insulation is one of the important factors of human thermal comfort assessment. Thermal insulation is the reduction of heat transfer (i.e., the transfer of thermal energy between objects of differing temperature) between objects in thermal contact or in range of radioactive influence. Thermal insulation can be achieved with specially engineered methods or processes, as well as with suitable object shapes and materials. Heat flow is an inevitable consequence of contact between objects of different temperature. Thermal insulation provides a region of insulation in which thermal conduction is reduced or thermal radiation is reflected rather than absorbed by the lower-temperature body. The term thermal insulation can refer to materials used to reduce the rate of heat transfer, or the methods and processes used to reduce heat transfer. Heat energy can be transferred by conduction, convection, radiation or when undergoing a phase change. For the purposes of this discussion only the first three mechanisms need to be considered. The flow of heat can be delayed by addressing one or more of these mechanisms and is dependent on the physical properties of the material employed to do this. Predicting the pattern of clothing adjustment to climate change can provide important basis for thermal comfort and energy consumption analysis. To achieve reliable results, it is necessary to provide precise inputs, such as clothing thermal parameters. These values are usually presented in a standing body position and scarcely reported locally for individual body parts. Moreover, as an air gap distribution is both highly affected by a given body position and critical for clothing insulation, this needs to be taken into account.

\section{KEYWORDS}

Thermal insulation, Cold-weather PPC, Clothing insulation, Clothing layers, Heat and mass transfer. 


\section{INTRODUCTION}

Clothing can be described in physical term of thermal insulation for the heat exchange of man with his immediate thermal environment [1]. In thermal comfort theory, clothing insulation is an important factor that affects thermal sensation [2]. People can adjust their clothing insulation to suit their own thermal comfort requirement $[3,4]$ and reduce energy consumption in buildings [5]. Therefore, clothing adjustment is a powerful behavioural adaption mode to weather change $[6,7]$. Predicting the pattern of clothing adjustment to weather change provides important basis for thermal comfort and energy consumption analysis [8,9].

Outdoor temperature is an important climatic factor to the change of indoor clothing. Various models were developed to predict the change of indoor clothing insulation with outdoor temperature, based on different regression functions. De Dear and Brager used an exponential decay function to fit the change of the mean clothing insulation for occupants of each building with the mean outdoor effective temperature at the time of the survey, based on ASHRAE RP-884 database. According to this model, $40 \%$ of the variance in clothing insulation was explained by variations in the outdoor climatic index [10]. Thermoregulation of human body aims at maintaining body core temperature in a narrow range and depends on metabolic heat production and the exchange of heat between skin and environment. When the human body is covered with clothing, it affects human physiological regulation mechanisms. Thus, the design and material aspects of functional clothing (e.g. protective or sport clothing) requires a detailed understanding of heat transfer processes. In the clothing research, heat transport is usually assessed by hot plates, thermal cylinders or thermal manikins in steady-state measurements. The experimental methods of assessing heat transfer require the availability of prototypes and testing facilities (e.g. climatic chambers) [11], which can be costly and time consuming.

Nowadays, global climate is changing and extreme cold spell incidents are becoming increasingly frequent and intense in recent years. During extreme cold spell incidents, people have a much greater chance to suffer from cold stress, which endangers human health, wellbeing and safety. Long-time exposure to cold stress could induce coldrelated illnesses and injuries, e.g., cracked skin, chilblain, frostbite, trench foot, cognitive impairments, hypothermia or even deaths [1214]. Clothing governs heat and mass transfer between the human body and the ambient environment. Local clothing thermal properties may vary considerably over the body, thus, having a major impact on the development of skin temperatures, sweating, and perception of thermal sensation and comfort [15]. Therefore, clothing, intended as a functional necessity to protect against harsh climate conditions and not as an ornamental accessory, has always been one of the main primary needs of mankind to adapt to the thermal outdoor environment. Indeed, variety in clothing is attributable also to the different local climate conditions where populations were living [16]. 
Thus, the human body covered in garments constitutes a complex system of thermal exchange, where heat and vapor produced by skin are first transferred to the gap between skin and the clothes and then throughout the textile material of the cloth, which is porous, towards the external environment [17]. Therefore, heat is transferred by means of conduction, convection and radiation phenomena, while water vapor by means of evaporation, absorption, condensation, deabsorption and transpiration (Fig. 1) [18].
Taken together, in cold-humid climates in winter, both moist clothing and high air humidity have profound effects on clothing performance and human thermal comfort. However, what are the thermal behaviours in the clothing microenvironment under actual wearing situations, and how to evaluate the clothing moisture effects caused by coldhumid environments on human thermal comfort remain unknown [19].

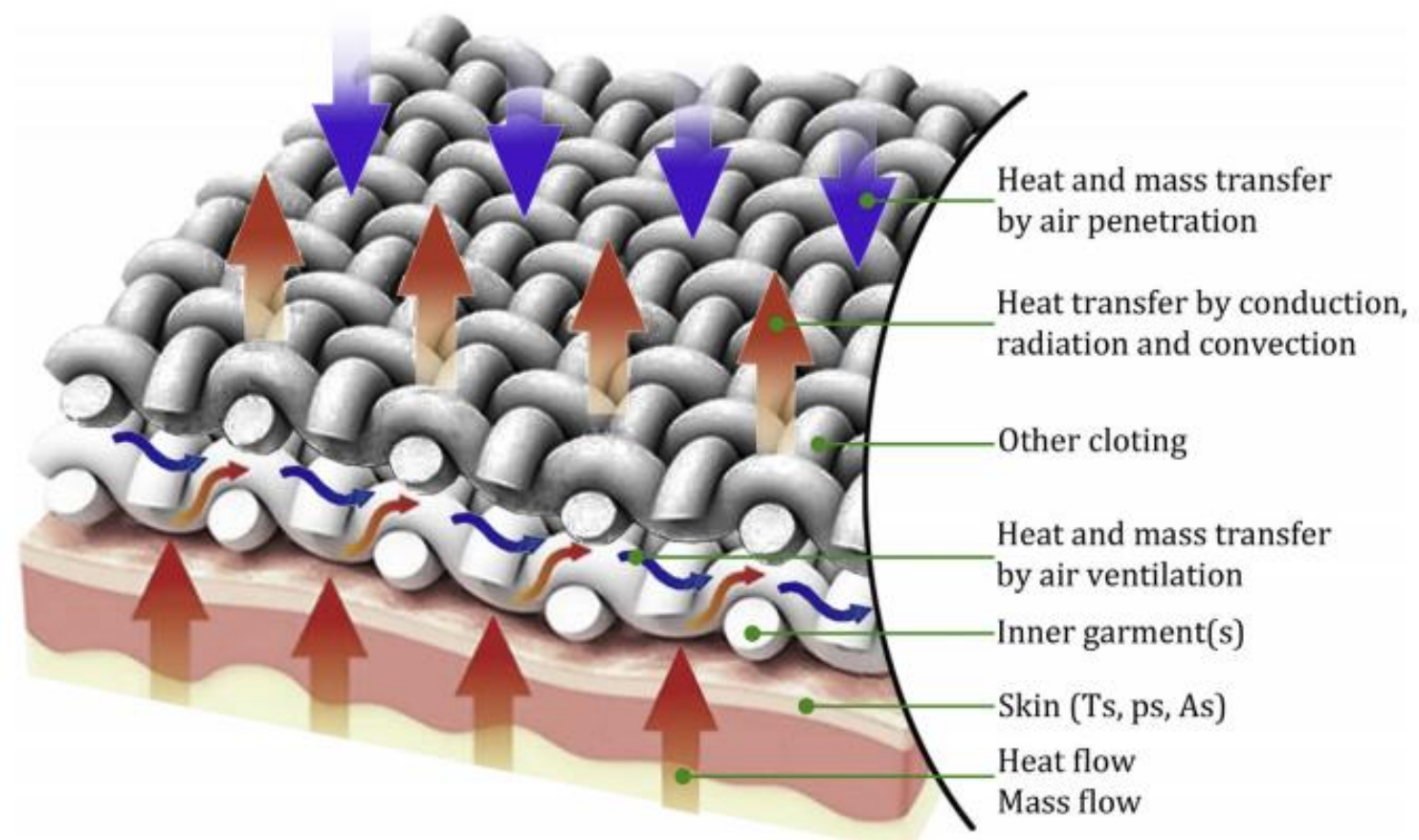

Fig.1. Heat and water vapor exchanges between the human body and the environment throughout clothes.

\section{Effect of clothing insulation}

The effect of various clothing insulation values on the time course of core temperature, mean skin temperature, mean trunk temperature and mean heaters' temperature is illustrated in Fig.2. All simulations were carried out at metabolic rate of 1.6 met under the ambient temperature of $15{ }^{\circ} \mathrm{C}$ and the PHCS's heating power was $20 \mathrm{~W}$. All the four studied temperatures, as expected, increased with the increasing clothing insulation. Though core temperatures at the four clothing insulation levels rose from $37.28^{\circ} \mathrm{C}$ to $37.81^{\circ} \mathrm{C}$ during the 60 -min simulations, clothing insulation had no pronounced effect on the increment of core temperature among the four simulation cases. 
Regarding the mean skin temperature, it dropped from $32.65^{\circ} \mathrm{C}$ to about $32.10^{\circ} \mathrm{C}$ during the initial $20 \mathrm{~min}$ and then was relatively stable throughout the remaining $40 \mathrm{~min}$ under the four clothing insulation levels (i.e., 1.0, 1.5, 2.0 and $2.5 \mathrm{clo}$ ). This revealed that all the four simulation cases could be able to help occupants maintain mean skin temperature in the thermoneutral range, despite those values were quite close to the lower limit (i.e., $32.0^{\circ} \mathrm{C}$ [20]). Similarly, the mean trunk temperature at the four levels of clothing insulation decreased from $33.67{ }^{\circ} \mathrm{C}$ to $32.90{ }^{\circ} \mathrm{C}$ within the initial 20

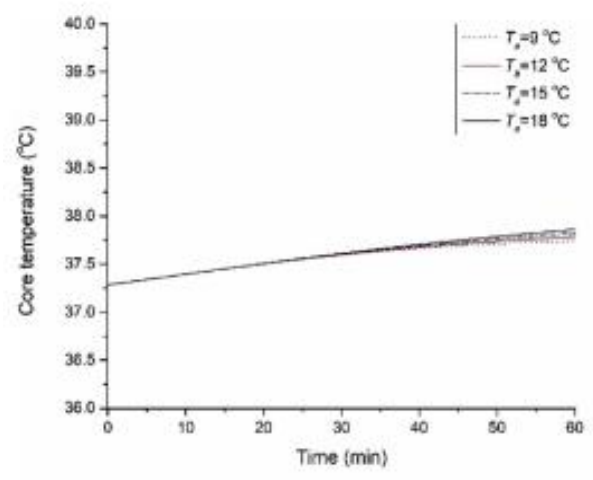

(a)

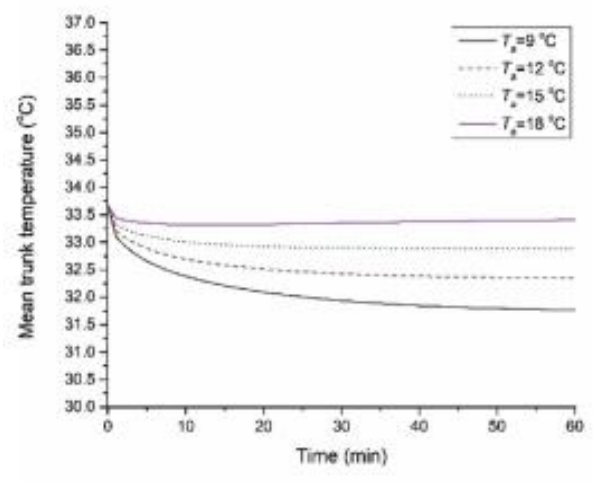

(c) min and it became stabilized throughout the remaining $40 \mathrm{~min}$ of the simulation. For the mean heaters' temperature, it was maintained at $36.19,36.32,36.40$ and $36.46{ }^{\circ} \mathrm{C}$ under clothing insulation levels of 1.0, 1.5, 2.0 and 2.5 clo, respectively. It might be argued from Fig.2 that clothing insulation had a limited impact on the further improvement of thermophysiological responses when the minimal insulation to attain occupant thermal comfort has been reached.

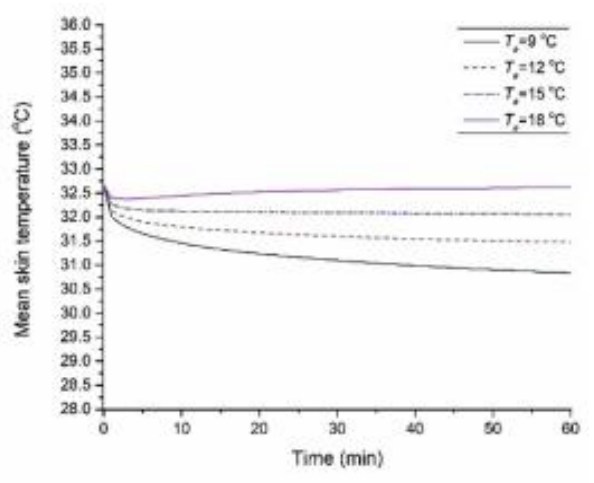

(b)

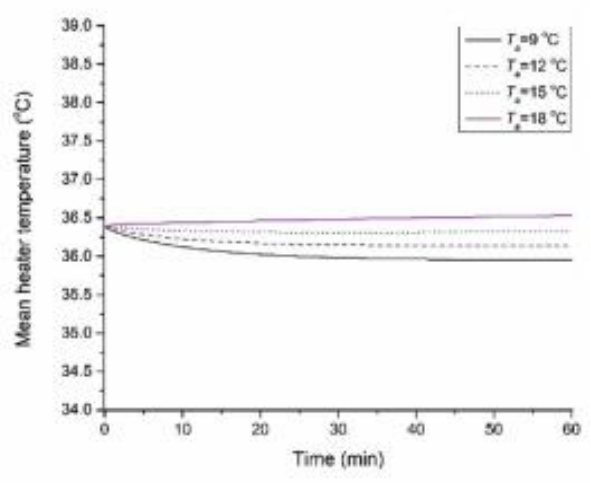

(d)

Fig. 2. Temporal variations of core temperature (a), mean skin temperature (b), mean trunk temperature (c) and the mean heaters' temperature (d) under four levels of clothing insulation (i.e., 1.0, 1.5, 2.0 and $2.5 \mathrm{clo}$ ) at $15.0^{\circ} \mathrm{C}$ indoor temperature. Input parameters in the simulations: Icl= 1.5 clo, $\mathrm{P}=20 \mathrm{~W}, \mathrm{M}=1.6$ met. 
Obviously, wearing a set of personal heating clothing with thermal insulation of $1.0 \mathrm{clo}$ and heating power of $20 \mathrm{~W}$ could help occupants attain thermal comfort at an indoor temperature of $15.0^{\circ} \mathrm{C}$ with a metabolic rate of 1.6 met. If no heating was supplied, the mean skin temperature would drop to $31.73{ }^{\circ} \mathrm{C}$ (see Fig. 3), which obviously fell outside of the thermoneutral skin temperature range. Thus, clothing incorporated with auxiliary heating is effective to help occupants attain indoor

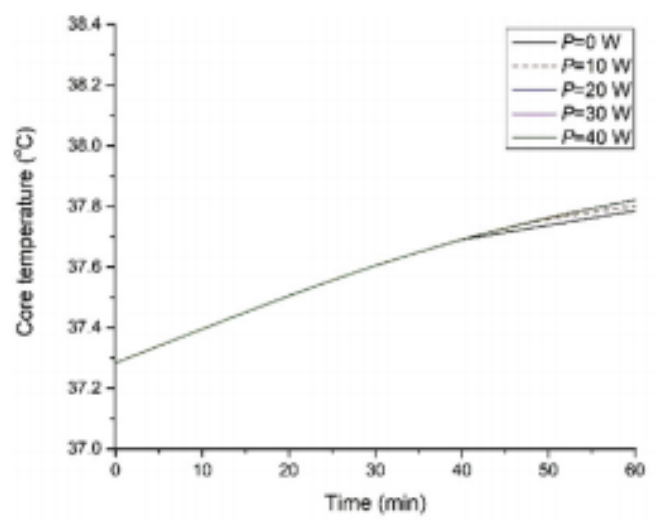

(a)

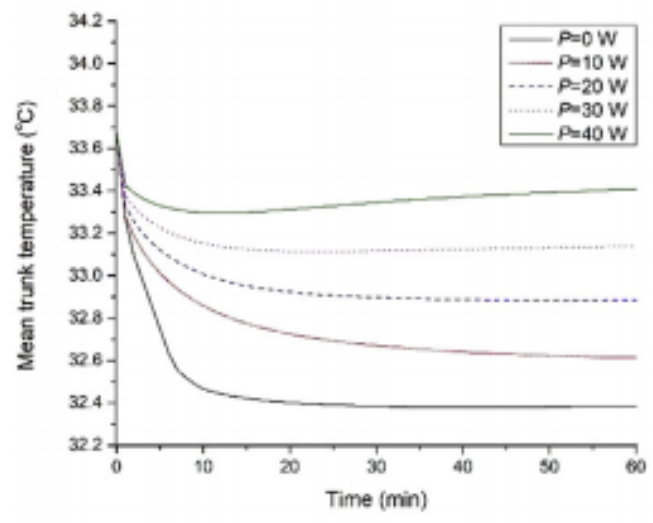

(c) thermal comfort in such a low indoor temperature. More important, the bulkiness of clothing did almost not change even six thin heaters were being embedded to the PHCS because the thickness of heaters is negligible (i.e., $1.2 \mathrm{~mm}$ ).

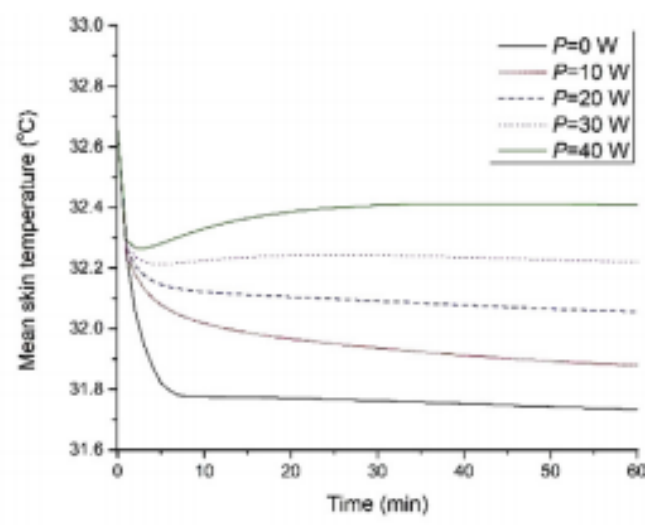

(b)

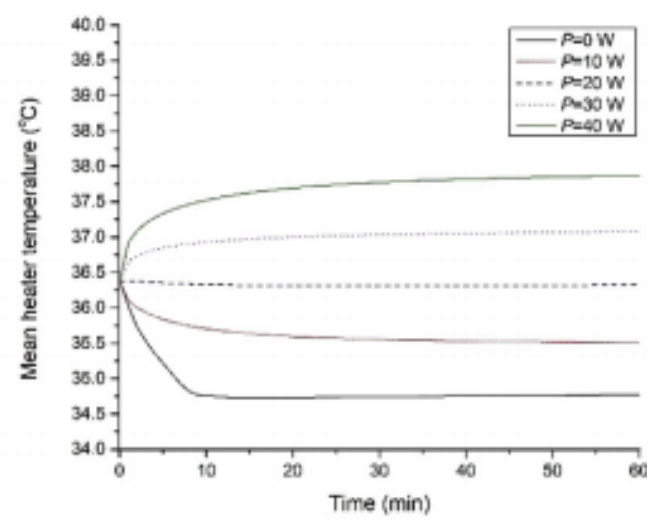

(d)

Fig.3. Temporal variations of core temperature(a), mean skin temperature (b), mean trunk temperature (c), and mean heaters' temperature (d) under four heating powers (i.e., 10, 20, 30, and $40 \mathrm{~W}$ ) and the control condition (i.e., $\mathrm{P}=0 \mathrm{~W}$ ). Input parameters in the simulation: $\mathrm{Icl}=\mathbf{1 . 5} \mathrm{clo}$, $\mathrm{Ta}=15.0^{\circ} \mathrm{C}, \mathrm{M}=1.6 \mathrm{met}$. 


\section{Cold-weather PPC}

Wearing cold-weather PPC influenced all measured physiological responses compared to wearing only a base layer. The 3-layer PPC increased MR by $8.8 \%$ and $10.0 \%$ during level and inclined walking respectively Fig.4. This corresponds to a $2.3 \%$ and $2.6 \%$ increase in MR per additional kg of clothing during level and inclined walking respectively. The same pattern was also observed for $\mathrm{VO}_{2}$ and $\mathrm{HR}$ (Table 1). Wearing the 3-layer PPC decreased
GE (Table 1) and increased muscle activation in all three muscles, seen as an increase in \% RMSmax by $9-29 \%$ compared with that wearing a base layer ensemble Fig.5. Walking with the 3-layer PPC ensemble was rated as more strenuous than walking with a base layer during both level and inclined walking (Table 2). The PCC did not alter stride frequency (Table 1) [21-28].

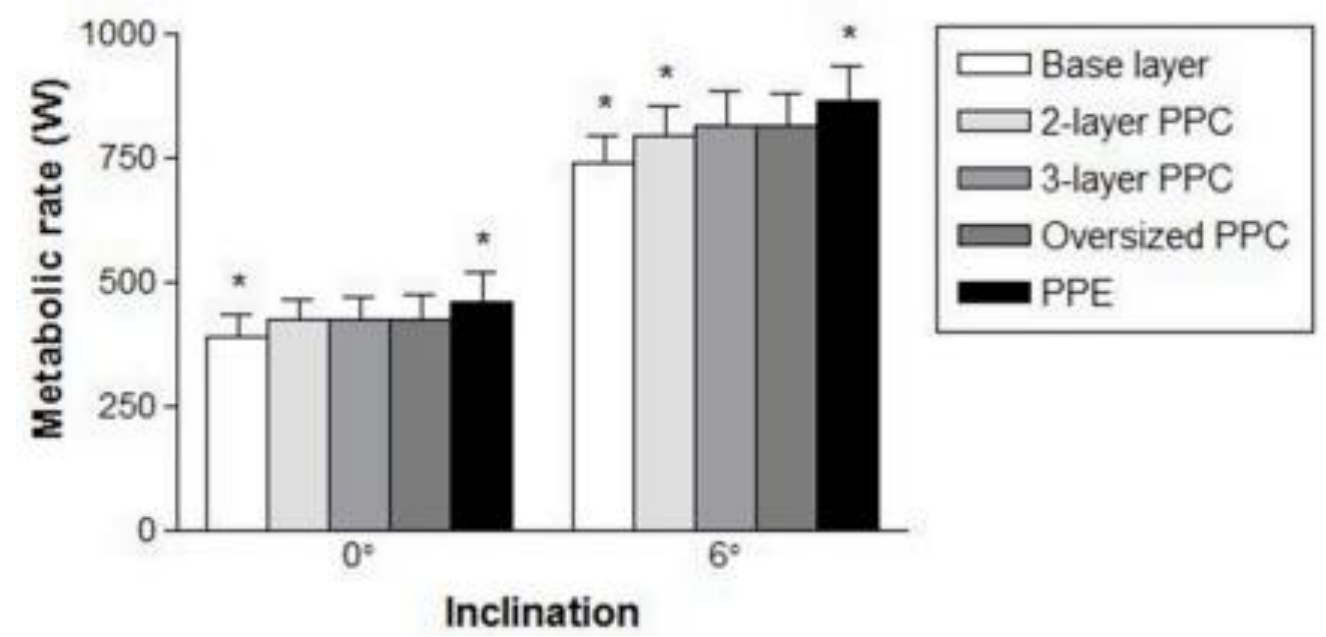

Fig.4. Mean ( \pm SD) metabolic rate during level $\left(0^{\circ}\right)$ and inclined $\left(6^{\circ}\right)$ walking $(5.0 \mathrm{~km} \mathrm{~h}-1)$ while wearing five different clothing ensembles. Significantly different from that wearing 3-layer PPC for level or inclined walking is indicated by asterisks. 


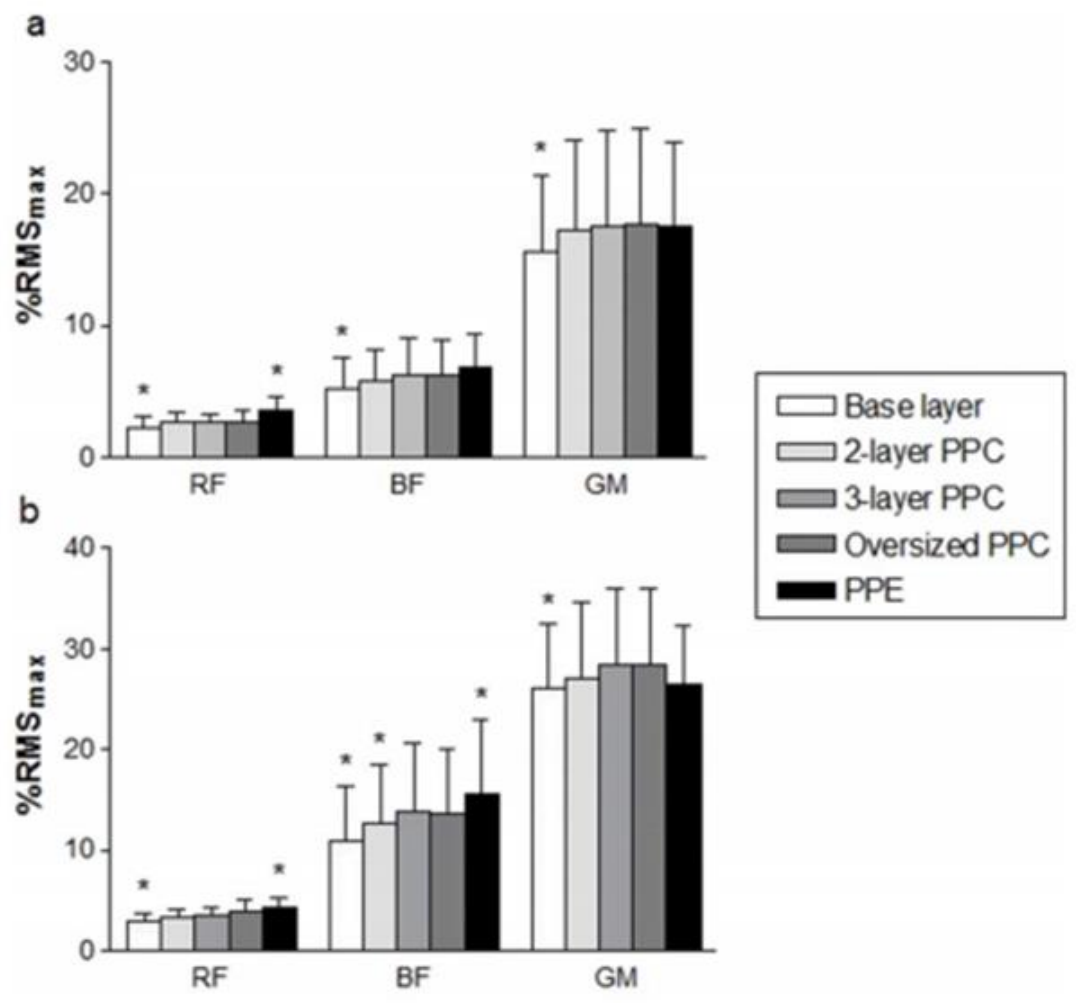

Fig.5. Mean ( \pm SD) muscle activation level (\%RMSmax) for rectus femoris (RF), biceps femoris (BF) and gastrocnemius medialis (GM) during (a) level $\left(0^{\circ}\right)$ and (b) inclined $\left(6^{\circ}\right)$ walking $(5.0 \mathrm{~km} \mathrm{~h}-1)$ while wearing five different clothing ensembles. Significantly different from that wearing 3-layer PPC for level or inclined walking is indicated by asterisk.

Table 1 Mean $( \pm S D)$ physiological responses and stride frequency at the end of the walking trials wearing five different clothing ensembles during level $\left(0^{\circ}\right)$ and inclined $\left(6^{\circ}\right)$ walking $\left(5.0 \mathrm{~km} \mathrm{~h}^{-1}\right)$.

\begin{tabular}{|c|c|c|c|c|c|c|}
\hline \multirow[t]{2}{*}{ Measurement } & \multirow[t]{2}{*}{ Inclination } & \multicolumn{5}{|c|}{ Clothing ensemble } \\
\hline & & Base layer & 2-layer PPC & 3-layer PPC & Oversized PPC & PPE \\
\hline GE (\%) & $6^{\circ}$ & $15.8 \pm 0.7$ * & $15.3 \pm 0.7^{*}$ & $15.0 \pm 0.6$ & $15.0 \pm 0.6$ & $14.6 \pm 0.7$ * \\
\hline \multirow[t]{2}{*}{$\mathrm{VO}_{2}\left(\mathrm{~L} \cdot \mathrm{min}^{-1}\right)$} & $0^{*}$ & $1.16 \pm 0.13^{*}$ & $1.25 \pm 0.13$ & $1.25 \pm 0.13$ & $1.26 \pm 0.14$ & $1.36 \pm 0.16^{*}$ \\
\hline & $6^{\circ}$ & $2.18 \pm 0.16^{*}$ & $2.33 \pm 0.17$ * & $2.38 \pm 0.19$ & $2.38 \pm 0.18$ & $2.53 \pm 0.19$ * \\
\hline \multirow[t]{2}{*}{ HR (beats $\min ^{-1}$ ) } & $0^{\circ}$ & $96 \pm 15^{*}$ & $98 \pm 15$ & $100 \pm 16$ & $102 \pm 16$ & $107 \pm 16^{*}$ \\
\hline & $6^{\circ}$ & $126 \pm 17$ * & $130 \pm 18$ * & $134 \pm 19$ & $135 \pm 18$ & $142 \pm 17^{*}$ \\
\hline \multirow[t]{2}{*}{$\mathrm{T}_{\mathrm{re}}\left({ }^{\circ} \mathrm{C}\right)$} & $0^{*}$ & $37.3 \pm 0.3$ & $37.3 \pm 0.3$ & $37.3 \pm 0.3$ & $37.3 \pm 0.4$ & $37.4 \pm 0.3$ \\
\hline & $6^{\circ}$ & $37.3 \pm 0.3$ & $37.3 \pm 0.3$ & $37.2 \pm 0.3$ & $37.2 \pm 0.4$ & $37.3 \pm 0.3$ \\
\hline \multirow[t]{2}{*}{$\mathrm{T}_{\text {skin }}\left({ }^{\circ} \mathrm{C}\right)$} & $0^{\circ}$ & $30.9 \pm 0.8$ & $29.7 \pm 1.2$ & $30.5 \pm 0.9$ & $30.6 \pm 0.9$ & $31.0 \pm 0.9$ \\
\hline & $6^{\circ}$ & $31.0 \pm 0.8$ & $29.8 \pm 1.3$ & $30.4 \pm 1.0$ & $30.5 \pm 0.7$ & $30.8 \pm 0.7$ \\
\hline Stride frequency & $0^{*}$ & $55.8 \pm 2.7$ & $56.0 \pm 2.7$ & $56.2 \pm 2.3$ & $56.1 \pm 2.5$ & $54.3 \pm 2.3 *$ \\
\hline (strides'min ${ }^{-1}$ ) & $6^{\circ}$ & $54.1 \pm 3.3$ & $54.9 \pm 2.9$ & $55.2 \pm 3.0$ & $54.6 \pm 3.4$ & $54.4 \pm 2.9$ \\
\hline
\end{tabular}

Table 2 Median [range] subjective scores of rate of perceived exertion (RPE), thermal comfort and thermal sensation when wearing five different clothing ensembles during level $\left(0^{\circ}\right)$ and inclined

$\left(6^{\circ}\right)$ walking (5.0 km h-1). 
The American Journal of Interdisciplinary Innovations and Research (ISSN-2642-7478)

Published: May 17, 2021 | Pages: 27-38

\begin{tabular}{|c|c|c|c|c|c|c|}
\hline \multirow[t]{2}{*}{ Measurement } & \multirow[t]{2}{*}{ Inclination } & \multicolumn{5}{|c|}{ Clothing ensemble } \\
\hline & & Base layer & 2-layer PPC & 3-layer PPC & Oversized PPC & PPE \\
\hline \multirow[t]{2}{*}{$\mathrm{RPE}^{\mathrm{a}}$} & $0^{\circ}$ & $8[6-11]^{*}$ & $9[7-12]$ & 9 [7-13] & $9[7-11]$ & $10[7-16]$ \\
\hline & $6^{\circ}$ & $10[7-13]^{*}$ & $12[9-14]$ & $13[8-16]$ & $13[9-15]$ & $13[10-17]^{*}$ \\
\hline \multirow[t]{2}{*}{ Thermal comfort ${ }^{b}$} & $0^{\circ}$ & $1[1-2]$ & $1[1-2]$ & $1[1-2]$ & $1[1-3]$ & $1[1-3]$ \\
\hline & $6^{\circ}$ & $2[1-3]$ & $2[1-2]$ & $2[1-3]$ & $2[1-3]$ & $2[1-3]$ \\
\hline \multirow[t]{2}{*}{ Thermal sensation $^{c}$} & $0^{\circ}$ & $0[0-2]$ & $0[-1 \cdot 1]^{*}$ & $1[0-2]$ & $1[-1 \cdot 2]$ & $1[0-2]$ \\
\hline & $6^{\circ}$ & $1[0-2]$ & $1[0-2]$ & $1[0-2]$ & $1[0-2]$ & $2[1-3]^{\star}$ \\
\hline
\end{tabular}

Significantly different from that wearing 3layer PPC for level or inclined walking. Multiple comparisons were used to identify possible differences between base layer and 3-layer PPC (effect of PPC), 2-layer PPC and 3-layer PPC (effect of layers), oversized PPC and 3-layer PPC (effect of fit/hobbling), PPE and 3-layer PPC (effect of PPE). $n=19$.

a 6, no exertion; 7, extremely light; 9 very light; 11, light; 13, somewhat hard; 15, hard; 19, extremely hard; 20, maximal exertion.

b 1, comfortable; 2, slightly uncomfortable; 3, uncomfortable; 4 , very uncomfortable.

C 3, hot; 2, warm; 1, slightly warm; 0, neutral; -1, slightly cool; -2 , cool; -3 , cold.

\section{Clothing layers}

The thermal insulation of a fabric used to make clothing depends on thermal insulation of fibres and yarns but also on fabric thickness, since the bulk of the thermal resistance is provided by the entrapped air in fabric pores [22]. For fabrics with low porosity the type of fibre and fabric construction may play a role since the ratio of fibre material to the air will increase. The value of thermal insulation can be measured on a hot plate or obtained from the literature [24-38]. In the theoretical model it is assumed that fabric properties are constant and the thickness of the fabric is homogeneous. The porosity and air permeability of the fabric in respect to mass transfer are neglected as forced convection in an enclosed air layer is not considered in the model. To understand the heat exchange between human body and environment through the clothing, the entire system can be divided into three different segments as shown in Fig. 6. 
(a)

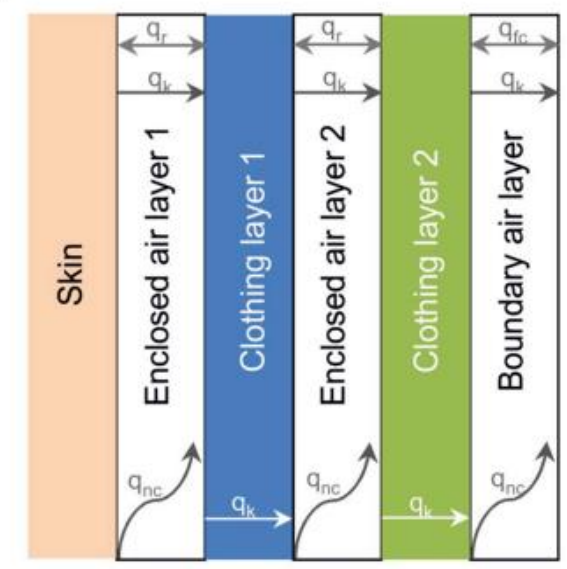

(b)

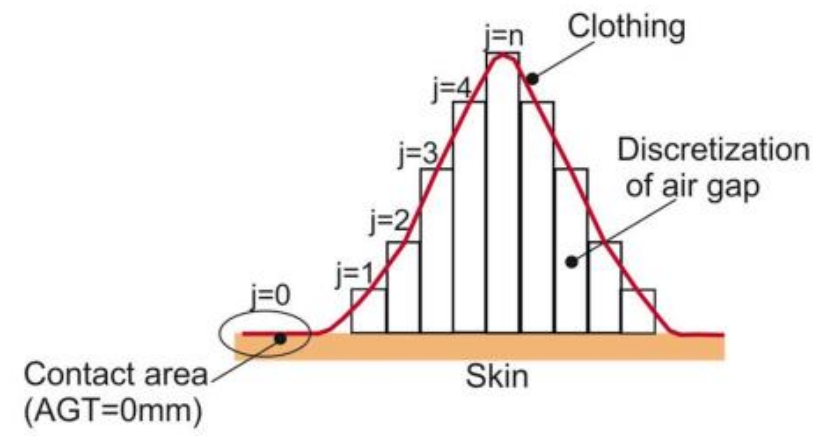

(AGT=0mm)

$q_{\mathrm{k}}$ :Conductive heat transfer $\mathrm{q}_{\mathrm{nc}}$ :Natural covective heat transfer

$\mathrm{q}_{\mathrm{r}}$ :Radiative heat transfer $\mathrm{q}_{\mathrm{fc}}$ :Forced covective heat transfer

Fig.6. Schematic diagram of heat transfer from human body to environment through clothing layers (a), principle of discretization of the enclosed air layer (b).

\section{CONCLUSIONS AND FUTURE PERSPECTIVES}

In the last decades, a broad research effort has been carried out on outdoor thermal comfort. The complexity of the topic, which is due to the many and rapidly changing variables, calls for the modeling of thermal comfort sensation for a normalized, standard subject. Clothing's thermal insulation is among the main variables, and it is linked to the clothes that individuals wear to defend themselves from the meteorological forcing of the outdoor environment. The wide variability of outdoor conditions does not allow hypothesizing clothing's thermal insulation as independent from the other factors characterizing climate and its daily and seasonal variability. Because, that clothing's thermal insulation preference, as expressed by an individual, depends also on personal thermal sensation linked to individual's comfort.

Thus, it appears as a necessary step to consider clothing's thermal insulation more in depth, by determining a mean preference value that also accounts for physiological factors linked to age and gender, Moreover, psychological and cultural factors influence clothing preferences, a specific population to the local climate zone. Based on the foregoing, our aim is to develop and introduce a new type of thermal insulation material for clothing in the future.

\section{REFERENCES}

1. Gagge, A. P., Burton, A. C., \& Bazett, H. C. (1941). A practical system of units for the description of the heat exchange of man with his environment. Science, 94(2445), 428-430.

2. Fanger, P. O. (1970). Thermal comfort. Analysis and applications in environmental engineering. Thermal comfort. Analysis and applications in environmental engineering. 
3. Parsons, K. C. (2002). The effects of gender, acclimation state, the opportunity to adjust clothing and physical disability on requirements for thermal comfort. Energy and Buildings, 34(6), 593-599.

4. $\quad$ Liu, W., Deng, Q., Ma, W., Huangfu, H., \& Zhao, J. (2013). Feedback from human adaptive behavior to neutral temperature in naturally ventilated buildings: physical and psychological paths. Building and Environment, 67, 240-249.

5. Newsham, G. R. (1997). Clothing as a thermal comfort moderator and the effect on energy consumption. Energy and Buildings, 26(3), 283-291.

6. Brager, G. S., \& De Dear, R. J. (1998). Thermal adaptation in the built environment: a literature review. Energy and buildings, 27(1), 83-96.

7. Liu, W., Zheng, Y., Deng, Q., \& Yang, L. (2012). Human thermal adaptive behaviour in naturally ventilated offices for different outdoor air temperatures: A case study in Changsha China. Building and Environment, 50, 76-89.

8. Morgan, C., \& de Dear, R. (2003). Weather, clothing and thermal adaptation to indoor climate. Climate Research, 24(3), 267-284.

9. Havenith, G., Fiala, D., Błazejczyk, K., Richards, M., Bröde, P., Holmér, I., ... \& Jendritzky, G. (2012). The UTCl-clothing model. International journal of biometeorology, 56(3), 461-470.

10. De Dear, R., \& Brager, G. S. (1998). Developing an adaptive model of thermal comfort and preference.
11. Tursunbayevich, Y. A. (2021). Investigation of Influence ofa New Twist Intensifier on the Properties of the Twisted Yarn. Turkish Journal of Computer and Mathematics Education (TURCOMAT), 12(5), 1943-1949.

12. Jones, D. M., Bailey, S. P., Roelands, B., Buono, M. J., \& Meeusen, R. (2017). Cold acclimation and cognitive performance: A review. Autonomic Neuroscience, 208, 36-42.

13. Yeganeh, A. J., Reichard, G., McCoy, A. P., Bulbul, T., \& Jazizadeh, F. (2018). Correlation of ambient air temperature and cognitive performance: A systematic review and meta-analysis. Building and Environment, 143, 701-716.

14. Ohashi, Y., Katsuta, T., Tani, H., Okabayashi, T., Miyahara, S., \& Miyashita, R. (2018). Human cold stress of strong local-wind "Hijikawa-arashi" in Japan, based on the UTCI index and thermo-physiological responses. International journal of biometeorology, 62(7), 1241-1250.

15. Havenith, G., \& Fiala, D. (2011). Thermal indices and thermophysiological modeling for heat stress. Comprehensive Physiology, 6(1), 255302.

16. Veselá, S., Kingma, B. R. M., \& Frijns, A. J. H. (2017). Local thermal sensation modeling - a review on the necessity and availability of local clothing properties and local metabolic heat production. Indoor air, 27(2), 261-272.

17. Salata, F., Golasi, I., Ciancio, V., \& Rosso, F. (2018). Dressed for the season: Clothing and outdoor thermal comfort in the Mediterranean population. Building And Environment, 146, 50-63. 
18. Brown, R. D., \& Gillespie, T. J. (1986). Estimating outdoor thermal comfort using a cylindrical radiation thermometer and an energy budget model. International Journal of Biometeorology, 30(1), 43-52.

19. Du, C., Li, B., Yu, W., Liu, H., Li, C., \& Yao, R. (2019). Moisture in clothing and its transient influence on human thermal responses through clothing microenvironment in cold environments in winter. Building and Environment, 150, 1-12.

20. Wang, F., Kang, Z., \& Zhou, J. (2019). Model validation and parametric study on a personal heating clothing system (PHCS) to help occupants attain thermal comfort in unheated buildings. Building and Environment, 162, 106308.

21. Renberg, J., Christiansen, $M$. T., Wiggen, $\varnothing$. N., Roeleveld, K., Bardal, E. M., \& Reinertsen, R. E. (2020). Metabolic rate and muscle activation level when wearing state-of-the-art cold-weather protective clothing during level and inclined walking. Applied ergonomics, 82, 102956.

22. Joshi, A., Psikuta, A., Bueno, M. A., Annaheim, S., \& Rossi, R. M. (2019). Analytical clothing model for sensible heat transfer considering spatial heterogeneity. International Journal of Thermal Sciences, 145, 105949.

23. AC08013703, A. (Ed.). (2008). Ergonomics of the thermal environment-Estimation of thermal insulation and water vapour resistance of a clothing ensemble. ISO.

24. Standard test method for thermal and evaporative resistance of clothing materials using a weating hot plate, (2002).

25. Bobozhanov, H. T., Juldashev, Zh. K., Sodikov, R. A., \& Ismatullaev, N. A. (2018). Issledovanija po izmereniju deformacii prjazhi pri pomoshhi opticheskih priborov [Studies to measure yarn deformation using optical instruments]. Universum: tehnicheskie nauki, (12 (57)). (in Russian).

26. Kosimov, A. A., Bakhriddinova, S. F. K., \& Abdulazizov, S. A. O. (2020). Classification Of Terry Products Made Of Natural Fiber. The American Journal of Engineering and Technology, 2(11), 133-141.

27. Mirxojaev, M. M., Atambayev, D. D. O., Lutfillaev, I. I. O., \& Jurayev, J. M. O. (2021). Change Of Cotton Fiber Quality Indicators Under Technological Processes. The American Journal of Applied sciences, 3(04), 241-249.

28. Atambayev, D. D., \& Hasanov, M. H. Analysis of Fibrous Waste Generated in the Preparation Departments of Spinning Mills and Cotton Processing.

29. Mirxojayev, M. M. (2020). Method Of Assessing The Bending Resistance Of Yarns In Suit Folding Fabrics. The American Journal of Engineering and Technology, 2(09), 98-101.

30. Yuldashev, J. Q., \& Bobojanov, H. T. (2020). Study Of The Influence Of The Parameters Of The Sampling Zone On The Condition Of The Capture Of Fibers By The Drum Teeth. The American Journal of Engineering and Technology, 2(08), 75-78.

31. Okboyev A.R. Directions for the introduction of an integrated quality 
management system to increase the competitiveness of light industry enterprises // South Asian Journal of Marketing \& Management Research (SAJMMR). Vol.10, Issue 11, November 2020 Impact Factor: SJIF 2020= 7.11. pp. 107-10.

32. Atambayev, D. D. O. (2020). Analysis Of Fibrous Wastes Generated During Spinning Of Cotton Fiber In The ReSpinning System. The American Journal of Engineering and Technology, 2(09), 86-90.

33. Kosimov, A. A., Bakhriddinova, S. F. K., \& Abdulazizov, S. A. O. (2020). Classification Of Terry Products Made Of Natural Fiber. The American Journal of Engineering and Technology, 2(11), 133-141.

34. Umarov, A. A., Ortikova, K. I., Sarimsakov, A. U., \& Kurbanov, D. (2020). Analiz upravlenija ruchnogo i avtomaticheskogo regulirovanija pitajushhih valikov pil"nogo dzhina [Analys Of Control of Manual And Automatic Regulation of The Feeder Roll Of The Saw Gin Stand]. Glavnyj redaktor: Ahmetov Sajranbek Mahsutovich, d-r tehn. nauk; Zamestitel' glavnogo redaktora: Ahmednabiev Rasul Magomedovich, kand. tehn. nauk; Chleny redakcionnoj kollegii, 22. https://7universum.com/ru/tech/archiv e/item/10693 (in Russian).

35. Akmal, U., Khamit, A., Akramjon, S., \& Muazzam, K. (2018). The Saw Gin Stand with Adjustable Movement of the Roll Box. Engineering, 10(08), 486.

36. Mirxojayev, M. M., \& ogli Ergashev, J. F. (2020). Analysis Of Tanda Yarn Fiber
Quality Indicators In Cotton Yarn Hardened Fabric Production. The American Journal of Engineering and Technology, 2(09), 82-85.

37. H.T. Bobojonov, A.A. Yusupov, J.Q. Yuldashev, M.R. Sadiko. Influence of deformation properties of yarn on the quality of knitted fabric. Test Engineering and Management. 2950229513

38. Tohirovich, B. H., \& O'g'Li, Y. A. A. (2020). Change Of Physical And Mechanical Properties Of Twisted Yarn During Rewinding. The American Journal of Engineering and Technology, 2(08), 64-69. 